\title{
Equity-Commodity Contagion During Four Recent Crises: Evidence from the USA, Europe and the BRICS
}

\author{
Ahmed AYADI $^{1}$, Marjène GANA ${ }^{2}$, Stéphane GOUTTE ${ }^{3}$, Khaled GUESMI ${ }^{4}$
}

\begin{abstract}
This study considers the findings of previous research concerning the volatility and correlation transmission between equity and commodity markets and attempts to document evidence of contagion between these markets during four crises using the International Capital Asset Pricing Model (ICAPM). We study existence of contagion transmission mechanism between regional equity markets (USA, Western Europe and the BRICS) and sixteen categories of commodities (Crude Oil, Natural Gas, Electricity, Metals, Precious Metals, Agricultural Oils, Chemicals, Feeds, Fibers, Forestry Products, Grains, Live Stocks, Oil Seeds, Seeds, Semi-Conductors, and Softs). We find that while most of the commodities decoupled from the Global financial crisis, the Irish Banking crisis and the European debt crisis, evidence of contagion were detected during the BREXIT.

Keywords: Equity-commodity contagion, Three-factor CAPM,

Financial crises
\end{abstract}

\section{Introduction}

Various studies have been proving the existence of equity market contagion between various stock markets across the globe (Bekaert and Harvey (1995),

\footnotetext{
${ }^{1}$ IHEC Carthage; Tunisie, Laboratoire d'Economie Dionysien (LED) - Universiy of Paris 8; France, Center of Research for Energy and Climate Change (CRECC)-Paris School of Business; France

${ }^{2}$ Université de Carthage, Ecole Polytechnique de Tunisie, Laboratoire d'économie et de Finance Appliquées

${ }^{3}$ University Paris-Saclay, CEMOTEV, France.

${ }^{4}$ Center of Research for Energy and Climate Change (CRECC), Paris School of Business, France
}

Preprint submitted to Elsevier

December 2020 
Rigobon (2002), Claessens and Forbes (2004) Bekaert et al (2014), Guesmi Nguyen (2014), Everaert Pozzi (2014), Jin (2016) among many others). This phenomenon is observed when shocks are transmitted from one market to another, especially during crisis periods. Consequently, investors are constantly searching for a way to protect their portfolios from the negative effects of these shocks. Contagion is transmitted by rather behavioral channels, yet these channels are originally driven by what happens to fundamentals during crisis times. Consequently, the only way for them to prevent this is to diversify their portfolios for hedging purposes. Since this is made by introducing other asset classes in the portfolios, the intuition drives us to check whether there are evidence of contagion between equities and the other asset classes. Accordingly, most of the previous studies focus on equity commodity shock transmission. This is due to the fact that since the subprime crisis of 2007, evidence of negative correlation was found between equities and various commodities, making them the best assets to be introduced in a portfolio for hedging. Blau (1944) provided some aspects of the commodity futures markets. He mentioned that their main role is to facilitate the shifting of risks due to unknown future changes in commodity prices because this risk cannot be covered by regular insurance measures. Barberis and Shleifer (2001) spoke about style investing, as when investors categorize a group of assets together and aim their funds towards these categories when they make their investment decisions. Assets are considered to belong to the same style when investors do not distinguish between them when investing. Intuitively, commodities could be considered as a style, such as small caps or large cap stocks. This is confirmed by Irwin and Sanders (2011), who report an increase in commodity prices during the great recession. This phenomenon could be explained by two reasons: either fundamental reasons as a rise in demand, or simply because large institutional investor turned large funds towards commodities in that period. This action is explained by their search for a safe hub in which they invest their money, since stock prices were dropping sharply. Intuitively, we consider that the increase in commodity prices is the result of the two reasons together, with financialization, i.e. the large participation of 
institutional investors in commodity markets, is the main reason. Our intuition is confirmed by the theoretical models of Basak and Pavlova (2013) and Basak and Pavlova (2016). In the first model, the authors establish a simple model containing an economy with a benchmark world with only retail investors and another world with both retail and institutional investors. Their findings suggest that institutional investors tend to demand more risky assets, especially those belonging to their benchmark index. Consequently, the prices of assets making this index rise. This rise in prices is accompanied by an increase in volatilities and correlations of these assets. In the second model, they use this model to track the effects of financialization on commodity prices, volatilities and correlations. Their findings suggest that when institutional investors tend towards commodities, their prices, volatilities and correlations do increase. This is driven by the increase in demand for commodities. This increase is also documented for the equity-commodity volatilities and correlations.

As various empirical studies documented the existence of increased correlations between equities and commodities during crisis times (Wen, Wei and Huang (2012), Lopez (2013), Mensi et al. (2013), Jebabli et al. (2014), Büyükşahin and Robe (2014), Khalfaoui et al. (2015), Berger and Salah Uddin (2016), Hasan (2017), Ruda and Saikat (2017), Yue-Jun et al (2017), Duc Khuong et al. (2020) among many others), we aim to document this phenomenon further. Our study aims to find evidence of contagion between equities and various commodities during four recent crises (the global financial crisis, the Irish banking crisis, the European debt crisis and the BREXIT). Since evidence of shock transmission were already documented between equities and various commodities (namely energy and food), our study extends the existing literature by analyzing this phenomenon from the point of view of contagion. We used benchmark indices of the equity markets of the USA, sixteen Westrn European countries and the BRICS, along with sixteen types of commodities. With the DCC-GARCH and the three factor International CAPM of Bekaert et al. (2014), we attempted to document evidence of contagion between these areas. To our knowledge, this is the first study to combine four crises and various equities and commodities 
from different regions to detect evidence of equity-commodity contagion. This aim is driven by the findings of Basak and Pavlova (2013, 2016), the increase in volatilities and correlations due to institutional investors' appetite for commodities. Since this behavior started at the great recession, it would have extended to subsequent crises. Our findings suggest that almost all of the commodities show evidence of decoupling from the global financial crisis, the Irish banking crisis and European debt crisis towards all the factors. The Irish banking crisis and the European debt crisis, which are considered as a consequence of the global financial crisis, continued with the initial decoupling effect. When it comes for the BREXIT, investors were already aware of the equity-commodity relationship. Consequently, they started investing in them to protect their portfolios, thus creating a positive contagion effect. This could be the reason behind the significant contagion observed for most of the commodities during the BREXIT. The rest of the paper is organized as follows: section 2 provides a summary of the theoretical background driving this study. Section 3 contains our empirical framework and results, and section 4 concludes.

\section{Theoretical background}

According to Blau (1944), commodity futures markets were established essentially to facilitate the shifting of risks due to unknown future changes in commodity prices. These risks cannot be covered by ordinary means of insurance. This lack of ordinary insurance creates a gap, from which arises the reason for the existence of commodity future markets. Trading in futures markets allows investors to minimize their risk in the cash market by assuming opposite risks in the cash market. This is translated in the real world by the actions of various investors in the market. Market participants tend to invest in commodity futures for speculative reasons, possibly hedging, by taking long or short positions depending on their needs. The event of receiving the actual commodity is very rare. Since commodities, amongst many other assets, are traded in the financial market, they could be considered as a separate asset class as they 
all share some similar characteristics.

Barberis and Shleifer (2001) define style investing as when investors, whether individuals or institutions, classify risky assets into different styles and move funds according to this ranking. Assets belonging to the same style are found to have an increase in their correlation. This categorization has mainly two aims: first, it facilitates the choice of assets to trade in. intuitively, it is easier to choose among known types of assets sharing common trademarks rather a large number of assets. Barberis and Shleifer (2001) define a style as a group made of the assets that investors do not distinguish between when making an investment decision. Consequently, small stocks, large stocks, or stocks to a particular industry or country could be considered as separate styles. Intuitively, commodities could also be considered as a separate style from equities, since they are related goods existent in the economy. The decision making process of style investing is mainly based of the style's past performance.

Irwin and Sanders (2011) reported that at least USD.100 billion of new investments in commodity futures between 2004 and 2008. This is due to the fact that negative correlations between stocks and commodities were reported during the 2007-2008 financial crisis, as mentioned by Yue-Jun Zhang et al. (2017). This phenomenon is called financialization of commodities. During this period, commodity prices augmented considerably. The cause of this rise is a matter of disagreement between various market participants. While some explain it by the large investments made by institutional investors during the great recession, others think that it is simply driven by fundamental factors, i.e. strong demand from developing nations such as India and China, since the developed world was suffering the consequences of the crisis. Intuitively, the two reasons taken by both sides could be actually related together. In fact, the heavy investments made by institutional investors in commodities raise their demand, which is the cause for the price pressures, driving the latters up. Consequently, the upward movement in commodity prices is due to fundamental causes which are themselves caused by financialization.

Eventually, financialization as a mean of speculation and hedging could be the 
first reason behind the considerable rise in commodity prices during the global financial crisis. This intuition was theoretically documented in Basak and Pavlova (2013). They establish a simple model in which two worlds, one with institutional investors and one without them, exist in the economy. Institutional investors tend to invest more in a benchmark index, and they tend to tilt their portfolios towards the stocks composing their portfolios. As they demand more risky assets than retail investors, the prices of these assets go higher. Consequently, both the index stock volatilities and the markets' aggregate volatility rise. Moreover, the augmentation in demand for risky assets by institutions raises the correlations among stocks belonging to their benchmark, which created an asset class effect, i.e. a style investment. Basak and Pavlova (2016) theoretical model extends that of Basak and Pavlova (2013) into analyzing the introduction of institutional investors in commodity markets and how this affects commodity prices. Their findings suggest that commodity futures prices, volatilities and correlations go up with financialization. Moreover, the equitycommodity correlations are also found to be increasing. Furthermore, financial markets transmit shocks to commodity future prices as well as commodity spot prices, inventories and storable commodity prices.

Various studies have documented evidence of contagion between equity and commodity markets. Wen, Wei and Huang (2012) used dynamic copulas in order to inspect the existence of contagion effect between energy and stock markets during the 2007 financial crisis. The date of September 15th 2008 is the one that breaks the sample into two sub-samples: the pre-crisis period and the postcrisis period. Since the aim of the study is to discover co-movements patterns of stock markets and oil during the crisis, the authors mention that it is necessary to check whether this contagion exists between these markets. Their findings proved the existence of contagion in terms of the definition of Forbes and Rigobon (2002): a significant increase in cross market linkages. This is translated by the significant increase in dependence between crude oil and stock markets after the fall of the Lehman Brothers. Thus the benefits of diversification of portfolios containing these assets would diminish. Moreover, they find 
that crude oil and US/Chinese equity markets were linked, regardless of these markets are booming or collapsing. Finally, the results also suggest that the contagion effect for China was much weaker than that of the US. Consequently, China will lead both the growth of the world economy and its energy demand. Lopez (2013) conducted a study aiming to detect implied volatility transmission between various asset classes. Noting that according to the author, implied volatility refers to the fact that volatility is derived from the prices of options on the asset whose volatility is being estimated. To work on her aim, the author used daily closing prices of five volatility indices, notably those of USD/EUR foreign exchange, commodity gold based index, oil price volatility index, VIX and Treasury bond volatility index VXTYN in a VAR model. The results show evidence of implied volatility transmission across equity and non equity markets in the USA. These implied volatilities are transmitted from equity to the other markets and vice versa. Moreover, they find that the economic news announcements have no role in transmitting implied volatility.

Mensi et al. (2013) tempted to investigate return linkages and volatility transmission between the equity and several commodities during the 2000-2011 time spans. They were driven by the fact both equity and commodity behaviors are becoming more and more sensitive to innovations since the financial liberalization. Moreover, commodities have been attracting more and more investors, making their markets more and more liquid. To serve their purpose, the authors used VAR-GARCH model to consider interdependence of returns, volatilities and correlations across the SP 500, beverage, wheat, gold and two oil price benchmarks: Brent and WTI. The findings show significant evidence of transmission. In fact, past shocks and volatilities of the SP500 influenced gold and oil markets. The strongest conditional correlations are found between the SP500 and gold and the SP 500 and WTI.

Büyükşahin and Robe (2014) use a non-public database made of trader positions in the SP500 and 17 US commodity futures markets (CBOT Wheat, Kansas Wheat, Corn, Soybeans, Coffee, Sugar, Cocoa, Lean hogs, Live cattle, Feeder cattle, Heating oil, Crude oil, Natural gas, Copper, Gold and Silver) 
between July 2000 and March 2010. The aim of their study is to provide novel evidence of financialization and to document aspects of its effect on the joint distribution of equities and commodities. Their findings suggest the correlations between equity and commodity indices increase with the participation of institutions, especially hedge funds, in commodity markets. This effect is even greater for institutions that hold positions in both equity and commodity markets.

Jebabli et al. (2014) were driven by the fact that food and energy prices exhibited upward volatilities and trend. As this issue has become a subject of debate since the financial crisis, since the volatility of agricultural commodities is driven not only by supply and demand but also by some other factors such as natural shocks, climate change, stock levels, links between energy and financial markets. Moreover, it is shown that oil prices are transmitted to food markets by transportation costs, fertilizer prices and the expanding use of agricultural commodities as feed stocks for biofuel production. The authors used a time varying VAR model (TVP-VAR) with stochastic volatility approach, mainly for its stability, to analyze shock transmission between international food, energy and financial markets. Energy markets are measured by oil prices and stock markets are introduced by MSCI world index. As for food markets, they contain crops, live stocks and forestry products. The findings suggest evidence of volatility spillover from crude oil and international stock markets to food markets. These shocks have immediate and short term impacts on food markets. These effects are observed more intensely during the 2007 financial crisis.

Khalfaoui et al. (2015) use multivariate GARCH and GARCH based wavelet analysis to check for linkages of crude oil and stock markets of the G7 countries. They study mean and volatility spillover between daily WTI oil prices and the benchmark indices of Canada, France, Germany, Italy, Japan, the United Kingdom and the United States. The findings show evidence of significant volatility spillover between oil and stock markets. Moreover, time varying correlations of various market pairs were documented. Equity prices of each of the G7 stock markets are affected by both their own lags and those of the WTI and other 
stock prices. As for mean spillover, they are documented as well between WTI oil prices and the equity markets. Moreover, the findings also show significant volatility spillover between the studied markets, as well as time varying correlations.

Berger and Salah Uddin (2016) mention that various investors are becoming more and more interested in commodities and an asset class serving primarily to diversify the risk. Equities and commodities are not driven by the same economic fundamentals and have weak dependence. Consequently, the authors use wavelet decomposition and time varying copulas on daily observations of the SP500, EURO STOXX, crude oil, heating oil, natural gas, copper, platinum, gold, silver and palladium prices in order to analyze the dependence structures between these various assets. Moreover, they introduce uncertainty index, thus their analysis focuses on the dependency on economic uncertainty and not on the drivers of commodity markets. The findings show that the dependence between stock returns and commodities appear to be weak, yet they are strong in the long and middle horizons. The same finding goes for the dependence between stocks and uncertainty. Furthermore, the results show that the financial crisis of 2008 strengthened the dependence between stocks and commodities and enlarged their degree of time variance.

Bekiros et al.(2016) focused on the increase of the attention given by academicians and investors to commodities, which is driven essentially by the increase in their financialization. They mention that this phenomenon is characterized by the increase in trading activity, the number and the type of traders since the 2000s. Institutional investors, index funds, sovereign wealth funds and retail investors are being more and more interested in commodities. This is due to the fact that they are becoming an asset class of their own, used mostly to diversify the risk issued from equities, especially in trembled times. The authors examined the dynamic causal linkages of equity and commodity future markets using complex network theory. They used daily observations of SP stock indices for ten industries and twelve commodities decomposed into three groups: energy, metals and agricultural products. The findings show emphasized disparity 
of correlations and entropy based centrality measures for all markets between crisis and non-crisis periods.

Hasan (2017) used MGARCH model to study the transmission of international energy price shocks to a variety of sectors in the Australian stock markets, notably classified by the GICS. The energy commodities are crude oil, natural gas and coal. For the GICS sectors of the Australian stock market (ASX), they consider energy, materials, industrials, consumer discretionary, consumer staples, health care, financials, information technologies, telecom and utilities. The findings exhibit significant dynamic movement of volatilities between these various assets.

Ruda and Saikat (2017) used DCC-MGARCH method and a generalized VAR based volatility spillover on daily observations of various asset indices such as commodity derivatives, bond market, equity market, foreign exchange market and gold market in India. The findings suggest that the degree of financial contagion is high between commodity and equities and low with gold. Moreover, stock market is a net transmitter of volatility, while bond, foreign exchange and gold markets are its net receivers. Furthermore, volatility is found to be transmitted to commodity market from equity market only. This volatility spillover varies over time, being higher at the global financial crisis and at the rupee depreciation in 2007-2008. Yue-Jun et al (2017) use a volatility threshold conditional correlation (VT-DCC) method on WTI oil price, Henry Hub Natural Gas, the VIX index and the European VSTOXX index. Their aim is to check if the volatility of crude oil and natural gas is influenced by that of stock markets, or whether these variables move all together. Answering this question enabled the understanding of the factors driving the movement of oil and gas prices. These factors are either their fundamentals or some other systemic component influenced by stock market's volatility. They identify two volatility clusters: one in 2008 due to the financial crisis and the other in 2014 caused by the structural low oil prices driven by the changing fundamentals. The findings support the idea of contagion from stock market panic to oil and natural gas markets, with the financialization of these two commodities remaining after the financial crisis. 
Yet no de-financialization is documented.

Duc Khuong et al. (2020) used an ARMA filter-based correlation approach in order to investigate the hedging versus financialization of several commodities vis-à-vis equity markets. They examined monthly inflation adjusted returns of cocoa, coffee, copper, corn, cotton, crude oil, gold, heating oil, platinum, silver, wheat, the SP Goldman Sachs commodity index and the SP500 index. This study is driven by the fact that fluctuations in commodity prices have considerable impacts on the economy. They are also seen as predictors of the future economic activity. While financialization is documented when the equitycommodity correlation is positive, the opposite case is considered hedging. The findings suggest that gold is considered a hedge against unfavorable events in the equity markets in the short term, yet the majority of commodities are treated as a separate asset class as their financialization increased. Moreover, these results are robust with inflation and they show the role of oil as a hedge in the 1990s. Finally, hedging and financilization of crude oil futures are found to be associated with global oil demand.

\section{Empirical framework}

In our study, we use a variety of weekly returns, ranging from March 12 th 2007 to December 31st 2018, in order to check for equity-commodity contagion during several crises. For equities, we used the benchmark indices of the SP 500 for the USA, Austrian ATX, Belgian BEL 20, Danish OMX Copenhagen 20, Finnish OMX Helsinki 25, French CAC 40, German DAX 30, Greek ATHEX 20, Irish ISEQ 20, Italian FTSE MIB, Dutch AEX, Norwegian OBX, Portuguese PSI 20, Spanish IBEX 30, Swedish OMX Stockholm 30, Swiss Mar-

ket Index and British FTSE 100. For the BRICS, our indices are Brazilian Ibovespa, Chinese Shanghai index, Indian BSE SENSEX, Russian RTX index and South African FTSE/JSE 40. For commodities, we used equally weighted indices which we constructed. They were categorized as follows: Crude Oil, Natural Gas, Electricity, Metals, Precious Metals, Agricultural Oils, Chemicals, 
Feeds, Fibers, Forestry Products, Grains, Live Stocks, Oil Seeds, Seeds, SemiConductors, and Softs. As for the crises, their time lapses are as follows:

- September 2007 to June 2011 for the subprime crisis ${ }^{5}$

- September 2008 to March 2011 for the Irish banking crisis ${ }^{6}$

- April 2010 to February 2012 for the Greek debt crisis ${ }^{7}$

- June 2016 to December 2016 for the BREXIT ${ }^{8}$

\subsection{Descriptive statistics and preliminary analysis}

\subsubsection{Descriptive statistics}

The descriptive statistics for commodities are reported in Table 1. It contains the number of observations, the minimum, mean, maximum, standard deviation, skewness, kurtosis, Jarcques-Bera test and ARCH test. The *, ** and $* * *$ represent the $10 \%, 5 \%$ and $1 \%$ significance levels consecutively.

The findings show that semi conductors are the ones with the lowest return, with a mean return between March 2007 and December 2018 reaching only $-0.168 \%$. On the other hand, Fibers are the commodities with the highest return over the studied period. Their mean return is $0.113 \%$. It is noticed that overall, energy commodities have lower returns than other commodities (except for livestock, which ranks with energy commodities in terms of mean return). Moreover, all energy commodities have negative mean return over the studied period. In terms of volatility, the opposite case of returns happened. The results show that energy commodities are the most volatile, while other commodities; notably agricultural ones; are the least volatile. These findings suggest that, in

\footnotetext{
${ }^{5}$ http://www.telegraph.co.uk/finance/financialcrisis/8592990/Timeline-of-world-financialcrisis.html

${ }^{6}$ http://www.telegraph.co.uk/finance/financialcrisis/8419616/Irelands-banking-crisistimeline.html

${ }^{7}$ http://www.telegraph.co.uk/finance/financialcrisis/9098026/Greek-debt-crisis-timelineof-main-events.html

${ }^{8}$ http://www.telegraph.co.uk/news/2016/06/24/how-britain-backed-a-brexit-the-keymoments-of-the-night
} 
periods of turmoil, it would be beneficial for market participants to invest in commodities, notably agricultural ones, in order lower the risk of their portfolios, since they exhibit low volatility. While forestry products have the lowest volatility of $1.14 \%$, natural gas is the most volatile commodity, with a standard deviation reaching $12.729 \%$. As for the other commodities, their volatility is relatively low. It ranges between $1.848 \%$ for metals $4.97 \%$ for crude oil.

As for the ARCH test, the results show that crude oil, electricity, precious

metals, agricultural oils, feeds, grains, oil seeds, seeds and chemicals show evidence of the existence of the ARCH phenomena. As for the other commodities, the ARCH test is insignificant. Turning to normality tests, the findings show that all commodities have normal distributions. This is shown by the low and insignificant skewness and excess kurtosis estimates.

For the ADF stationarity test, the results are mentioned in Table 2. The findings show that only crude oil, natural gas, grains and chemicals have a test statistic more negative than the critical values, i.e. show evidence of stationarity. And for the other commodities, the results show that the $\mathrm{H} 0$ of unit root is accepted. This is clearly seen in the ACF and PACF plots of Figure 1.

\subsubsection{Preliminary analysis}

Table 3 presents the correlation matrix between the commodities and the equity return factors for the whole period. The values with * indicate a significance at the $5 \%$ level. Starting with crude oil, it exhibits significant correlations with the three factors. Yet this correlation is rather weak, varying between $8.42 \%$ with the US factor to $12.62 \%$ with the BRICS factor. As for the Europe factor, the correlation is significantly negative, reaching $-14.05 \%$. Turning to natural gas, it shows significantly strong positive correlation with Europe (84.68\%) and significantly weak negative correlation with the BRICS (8.47\%). As for the US, the correlation is insignificant. Electricity is significantly, positively and weakly correlated with the US and the BRICS, with correlation coefficients under $11 \%$. The correlation between metals and all the three factors is positive, yet it is weak and insignificant. The same case applies for chemicals and semi- 
conductors. These coefficients do not exceed $6 \%$. As for precious metals, along with grains and oil seeds, they exhibit positive and significant correlations with the US and the BRICS. Yet these correlations are weak, ranging between $8 \%$ and $12.8 \%$. For agricultural oils, the only significant correlation coefficient is that with the BRICS, it has a value of $9.18 \%$. Feeds and forestry products correlate significantly with the US only, with weak positive coefficients of $11 \%$. As for fibers, live stocks and softs, their correlations with all the factors are insignificant and weak. These results suggest that overall; the equity-commodity relationship is rather weak, with most of the coefficients being insignificant. Moreover, most of the significant correlation coefficients are negative. Consequently, we predict that the equity-commodity contagion would be inexistent for most of the commodities. The ones that would show significant evidence of contagion would probably decouple, showing promising portfolio diversification elements.

We turn our focus to the evolution of the stock and commodity prices. This is done by looking at the graphics of Figure 2. For part, the red graph depicts the whole period, the blue graph is for the global financial crisis, the green graph is for the Irish banking crisis, the pink graph s for the European debt crisis and the purple graph is for the BREXIT.

Overall, the stock prices exhibit downward movement; after being at a high level; at the beginning of each crisis. This movement reaches a trough then price rise again, but to a level inferior of the pre-crisis peak. For the Irish banking crisis and the European debt crisis, the further downward movement at their beginning could be due to the fact that their time lapse is within the global financial crisis, which creates double augmented effect. As for commodities, the overall trend of their prices is an upward movement after being at a low level during the crises. This could be a reason behind the overall negative correlation coefficients shown in Table 1.

Figure 3 shows the dynamic correlations calculated with the DCC-GARCH for each of the commodities with the three factors for the whole sample. The red graph shows the correlation of the commodity with the European factor, the 
blue graph is with the US factor and the green graph is with the BRICS factor. The graphs show all of the correlations are weak and close to zero. Besides, most of them are rather negative. Moreover most of them show troughs during some of the crisis periods. These findings allow us to predict that the interdependence between equities and commodities are weak and negative, which leads us to anticipate that commodities would decouple from the crises.

To analyze the betas, we focus on Figure 4. Figure 4 plots the beta coefficients for each commodity with each factor for the whole period. The analysis of the beta allows us to check the significance of the dependence structure between equities and commodities, thus we can predict the existence or the absence of contagion. Starting with crude oil, its beta with Europe seems to be relatively constant, with downward trough at the period combining the end of the global financial crisis and the Irish banking crisis and the beginning of the European debt crisis, and another trough in the middle of the BREXIT. This increase in the negative correlation predicts a decoupling. As for the US, the beta is mostly positive and smaller than 1. Moreover, its pattern suggests an increase in positive dependence, predicting a contagion. The same goes for the BRICS factor, i.e. the pattern predicts contagion, yet the beta is larger than 1 . Turning to natural gas, its beta for the three factors is almost zero for the whole period, except some peaks outside of crisis periods. Moreover, the peaks during the BREXIT predict contagion, while the other crises need further examination, yet we can predict a small or even insignificant contagion. Electricity shows a negative beta with Europe and a positive one with the US and the BRICS. While the first exhibits a downward movement, predicting decoupling, the second shows a relatively stable movement with a small upward trend. This suggests a small contagion effect that needs deeper examination. As for the BRICS factor, the beta shows clear upward movements during crisis times, predicting an increased dependence or contagion. The beta of metal with all the factors is very close to zero for almost the whole period. Thus evidence of contagion or decoupling would need a deeper look. It is not the case for the BREXIT, in which the beta shows an upward movement, suggesting a significant contagion effect. The 
beta relating precious metals and Europe is negative and exhibits a downward movement, suggesting a decoupling. As for the US and the BRICS, the beta is positive and highly volatile, thus the need for a deeper look. The figure shows a negative beta relating agricultural oils and Europe and the US, this suggests evidence of decoupling. While the relation with Europe shows a downward movement, it shows an upwards one with US, yet it is always negative. For the BRICS, the beta is positive and shows a generally upward trend during crisis periods, predicting evidence of contagion. Chemicals show an almost constant and zero beta with Europe and the US, suggesting the absence of contagion. As for the BRICS, the trend is upwards despite its volatility, thus we anticipate a significant contagion effect during all the crises. For feeds, we could anticipate a decoupling with Europe, since the beta lies below zero and shows a downward overall trend. As for the US and the BRICS, the betas are too volatile to judge, thus the need for a deeper analysis. The same goes with forestry products. The betas of fibers with all the factors are null for the three factors, predicting the absence of contagion. The same goes for live stocks. As for grains, the betas are positive and volatile, with relatively upward movements during the crises. We could predict contagion, but it is preferable to take a deeper look into the crisis periods. The same goes with oil seeds. The negative betas relating seeds with both Europe and the US allow us to predict decoupling. As for the BRICS factor, the beta is near zero and fluctuating, thus we would need further analysis. Semi conductors have a negative beta with Europe, predicting a decoupling. Yet some upward movements would push us to look deeper. As for the BRICS and the US, the constant zero beta suggests the absence of contagion. Finally, we could anticipate a small decoupling for softs with Europe. As for the US and the BRICS, we need a deeper look.

\subsection{Interdependence model}

In this part of the study, we estimate the interdependence model. It is presented by the following Equation 1 : 


$$
R_{i, t}=R_{i, t-2}+\beta_{i, 0}^{\prime} F_{t}+e_{i, t}
$$

Where:

- $R_{i, t}$ is a factor made of the returns of a commodity type $\mathrm{i}$; an equally weighted factor made of the returns of the commodities included in a specific category - $R_{i, t-2}$ is the returns of the commodity lagged by 2 observations

- $F_{t}$ is a vector made of the three CAPM factors, from which shocks are supposed to be transmitted. It is made of the European factor; which is a value weighted factor of the returns of the benchmark stock market indices 16 developed European markets, the US factor made of the returns of the SP 500 and the BRICS factor; a value weighted factor made of the returns of the benchmark indices of the BRICS countries

- $e_{i, t}$ is the residual term

It should be mentioned that the betas estimated here are static.

The findings are reported in Table 4.They show that overall; there is no interdependence between commodities and equities. These results have some exceptions. For instance, oil and natural gas exhibit evidence of strong interdependence towards Europe, with the betas being large and significant at the 1\% level. As for crude oil, the beta is negative, suggesting that the prices of crude oil and those of the European countries move in opposite directions. As for the US factor, natural gas shows again its negative significant interdependence with the SP 500. Moreover, feeds and forestry products show evidence of interdependence with the US factor. Yet this interdependence is relatively low, with betas about 0.2 for forestry products and 0.5 for feeds. This interdependence is nevertheless significant at the $1 \%$ level. Turning to the BRICS factor, the findings show evidence of weak interdependence with some of the commodities. The only significant beta coefficients are those of crude oil, electricity, precious metals and grains. These betas range between 0.25 for grains and 0.64 for crude oil, all significant at the $5 \%$ level. These findings suggest that when there is no control for turmoil periods, commodities show no interdependence with equities. 
This means that overall; commodity markets and equity markets are generally not related. This suggests that when equity markets are trembled, investing in commodities would be a safe way to protect investors' portfolios from the potential negative consequences of a crisis.

\subsection{Contagion model}

In this part of the study, we turn our focus to detecting contagion from equity to commodity markets. To do so, we estimate the contagion model, presented as follows:

$$
\begin{gathered}
R_{i, t}=R_{i, t-2}+\beta_{i, t}^{\prime} F_{t}+\mu_{i, 0} C R_{t}+e_{i, t} \\
\beta_{i, t}=\beta_{i, 0}+\gamma_{i, 0} C R_{t}
\end{gathered}
$$

Where

$R_{i, t}$ is a factor made of the returns of a commodity type $\mathrm{i}$; an equally weighted factor made of the returns of the commodities included in a specific category - $R_{i, t-2}$ is the returns of the commodity lagged by 2 observations

- $F_{t}$ is a vector made of the three CAPM factors, from which shocks are supposed to be transmitted. It is made of the European factor; which is a value weighted factor of the returns of the benchmark stock market indices 16 developed European markets, the US factor made of the returns of the SP 500 and the BRICS factor; a value weighted factor made of the returns of the benchmark indices of the BRICS countries

- $C R_{t}$ is a crisis dummy variable taking the value of one when a crisis appears and zero otherwise.

- $\beta_{i, 0}$ represents the coefficient of interdependence, i.e. we document evidence of interdependence towards a factor is this coefficient is significant

- $\gamma_{i, 0}$ is the coefficient measuring factor related contagion. When this coefficient is positive and significant, it detects evidence of contagion related to the factors included in the $F_{t}$ 
- $\mu_{i, 0}$ is the coefficient measuring contagion beyond the factors. This kind of contagion is detected when this coefficient is negatively significant.

- $e_{i, t}$ is the residual term

Unlike the interdependence model, the betas used here are dynamic. These are obtained by estimating the returns of the BRICS and the factors using the multivariate DCC-GARCH model of Engle (2002).

The findings of the contagion model are reported in Tables 5 to 8 . The *, ** and ${ }^{* * *}$ represent the $10 \%, 5 \%$ and $1 \%$ significance levels consecutively. We also support our analysis by looking at Figure 5, presenting the beta of the commodities with all the factors at each of the crises periods.

Starting with the global financial crisis, the results are shown in Table 5. Crude oil shows no evidence of factor related contagion with Europe. Despite the significant negative beta, the downwards movement was not significant at the beginning of the crisis. The surprising result is the decoupling with the US factor. Despite the increase in positive dependence, the gamma estimate is found small and negative. This small decoupling effect could be explained by the opposite side movement of oil prices and the SP500 prices. Unlike the fall of American equity prices, oil prices rose at the start of the GFC. This could be explained by the increase of oil demand of developing nations, such as mentioned by Irwin and Sanders (2011). For the BRICS factor, there is no evidence of contagion. The insignificance of the gamma estimate is due to the relatively constant beta at the rise off the crisis and its sharp downward movement following a sharp increase. For natural gas, it decouples with Europe due to the opposite side movement of the assets' prices during the beginning of the crisis. Also, the equity prices rose sharper than gas prices after the trough. As for the BRICS factor, despite a significant interdependence due to the same price movement, it appears that the relatively constant dependence observed for most of the crisis period killed the contagion phenomenon. Electricity exhibits factor related contagion to Europe and the US. While it decoupled with the first, because of the downward movement of the dependence during the crisis, the decoupling 
with the US is due to the opposite side movement of the assets' prices, creating several troughs in the dependence, despite the positive beta the overall upward movements. As for the BRICS, the results show a significantly positive gamma estimate, reflecting the upward movement in the dependence during most of the crisis period. Metals decouple from Europe and the BRICS. This is explained by the opposite price movement at the start of the event and the fact that metals prices rose sharper than the equity prices following the trough. This happened despite a significant positive dependence. As for the US factor, the high fluctuation of the dependence made it significantly small, thus eliminating the contagion effect. The same reasoning goes for explaining the decoupling of precious metals from Europe and the US and the absence of contagion with the BRICS. The significantly positive $\mu$ estimate of precious metals explains the decoupling, yet it is unrelated to the factors. The factor related decoupling of agricultural oils is explained by the negative and downward dependence. As for the US, the dependence is negative and highly volatile, which killed the contagion effect but kept a significant dependence. There was significant contagion with the BRICS due to the significant dependence and its upward movement. Feeds and fibers decouple from the US factor despite a positive dependence. While feeds' prices moved at the opposite direction with US equities at the rise of the crisis then rose sharper, fibers' prices had an upwards movement during the crisis period. As for Europe and the BRICS, the absence of contagion is due to the relatively constant dependence near zero. Thus this dependence is significant due to its volatility at some time intervals. Forestry products show evidence of factor related decoupling with the US and the BRICS. While the dependence is significant due to its volatility, the decoupling is explained by the very sharp rise in their prices compared to equities, thus they could manage to survive the crisis quicker. For Europe, there was no contagion due to the relatively constant dependence. Grains decouple from Europe and the US, as the gamma estimate is significantly negative, despite the positive significant dependence. Again, this result is explained by the opposite side price movement at the dawn of the crisis and the sharper price increase of grains at its end. 
As for the BRICS, there was no contagion despite significant interdependence due to the latter's volatility. As for live stocks, despite the significant negative dependence, there was evidence of significant contagion, as the gammas are positive. The reason behind this is the increased dependence at the beginning of the crisis and at its end. Oil seeds decouple from Europe and the US for the opposite side price movement reason mentioned for previous commodities, despite a positive dependence due to the increase in the beta and its volatility. The same reasoning goes for explaining the similar results for seeds. The negative dependence alongside with the fact that semi conductors' prices moved at the same direction with Europe explain the decoupling towards this factor. For the us and the BRICS, contagion is insignificant due to the fact that dependence was practically constant and close to zero. Yet it was detected due to the price movement, yet it is still weak. Moreover, the findings show a significantly negative mu estimate, suggesting evidence of contagion beyond the factors. Softs show only negative interdependence with Europe, due to the constant beta. As for the US, the results show evidence of contagion due to the relatively upwards movement of the dependence with a large peak at the end. The large volatility of the softs' dependence with the BRICS killed its significant and took off the contagion effect. Chemicals decoupling with the three factors is explained by the price movements, as seen in Figure 2-j. the movement is at opposite direction at the beginning and with a sharper rise in the commodity's prices at the end. This decoupling happened despite a positive significant interdependence explained by the relative rise in the beta during the crisis.

Now we focus on the Irish banking crisis. The findings are reported in Table 6 . Crude oil shows significant decoupling from the crisis, as the dependence appear to be negative by looking at the graphs of Figure 2 and 5 . As for the US factor, the heavy fluctuations caused a significant dependence, yet it eliminated the effect of contagion since there was no obvious upward or downward trend. The significant factor related contagion with the BRICS is due to the sharp increase in dependence between the returns of the equities and crude oil at the beginning of the crisis. Turning to natural gas, it is mostly constant at zero with Europe, 
thus the absence of contagion. Yet the sharp increase during the crisis created an interdependence effect. As for the US and the BRICS, interdependence was significant due to the fluctuation of the beta during the crisis. This strongly correlated relationship in absence of an obvious trend eliminated the significance of contagion. The findings for electricity show that it decoupled from the crisis with Europe, due to the downward trend of the dependence during the crisis. Yet it shows solely interdependence with the US. As for the BRICS, evidence of factor related contagion is found. Contagion here is explained by the positive dependence with the BRICS factor, combined with a generally upward trend at the beginning of the crisis and a gradual decline afterwards. Metals decoupled with the European factor because of the increase of the dependence after a sharp increase in the middle of the crisis time. As for the US and the BRICS, only interdependence is documented. While it is explained by the fact of the fluctuation of the beta near zero for the US, it could be due to the fact that the peaks and troughs with the BRICS are relatively equal, which would eliminate a significant contagion effect. It is worthy that the fundamental reason behind decoupling is that at some times during a crisis, there was an opposite side comovement between equities and commodities. Precious metals decoupled from Europe due to the negative dependence during the crisis, explained by some opposite-side co-movement of prices. As for the US, a very small but significant factor related decoupled is found. It could be due to the relatively sharp troughs during the crisis. yet is magnitude is due to the fact that the prices actually did move at the same direction. For the BRICS, no significant contagion or decoupling is found because of the practically constant dependence after a sharp decrease at the beginning of the crisis. Yet the positive dependence is due to the similar price evolution pattern. This evidence would suggest rather contagion, but a significantly positive $\mu$ estimate suggests that there was decoupling due to elements unrelated to the factors. The findings for agricultural oils show decoupling with Europe, explained by the negative downward dependence during the crisis and some opposite side co-movements at some points. As for the US, the fluctuation of dependence shows a negative integration, yet the heavy volatility 
eliminated contagion effect. As for the BRICS, significant evidence of contagion is reported. It could be explained by the large peaks at some points of the crisis and the fact that prices moved at the same direction. Turning to feeds, their results show only negative interdependence with Europe, which is due to the negative dependence which was rather constant for most of the crisis period. As for the US factor, despite for the significantly positive dependence (as the prices moved in same direction); observed within the movement of the dynamic beta, the relatively sharp troughs, especially the one at the beginning of the crisis, shows the decoupling. This could be explained by the fact that the Irish banking crisis is a consequence of the global financial crisis, thus the US equities -feeds relation during that crisis just continued. As for the BRICS factor, there was a sharp increase of dependence at the beginning of the crisis period, explained by a similar pattern of asset price variation. Consequently, significant factor related contagion is detected. Turning to fibers, the findings show significantly positive interdependence with all the factors, which is explained by the fact that the prices moved at the same direction. Yet the relatively weak dependence, observed in the practically zero betas, explains the inexistence of significant contagion. But a significantly positive $\mu$ estimate suggests a decoupling caused by elements beyond the factors. Forestry products show evidence of decoupling, shown by the downward movement in the dependence by the dynamic beta. As for the US factor, there was a mall decoupling in spite of a positive dependence and a same-side price co-movement. We could explain it by a continuation of the effects of the previous crisis, i.e. the global financial crisis. As for the BRICS factor, the beta fluctuates practically near zero with some peaks and troughs throughout the crisis. Consequently, only a significant interdependence was detected. The relatively low constant dependence of grains with Europe is the reason behind the absence of contagion (only interdependence is detected, due to a peak in the middle of the crisis time). As for the small decoupling from the US, we could say that it is caused by the time intervals in which prices moved at opposite side, despite an overall positive dependence. As for the BRICS, a small contagion effect was detected, due the gradually upward dependence. 
This is caused by the fact that prices practically moved together for most of the crisis period. Live stocks show evidence of factor related contagion with Europe and the USA. Despite a negative dependence with a downwards pattern, live stocks prices, alongside with those of European and American equities, show the same pattern. As for the BRICS factor, the results show negative significant interdependence, exhibited by an opposite-side co-movement of prices. Yet the dependence fluctuated around zero for most of the crisis time, explaining the absence of contagion. Oil seeds show only interdependence with Europe. While the positive dependence is due to the prices moving together, it is very close to zero, thus the absence of contagion. The same result is found for the BRICS factor, yet the absence of contagion is probably explained by a sharp increase followed by a sharp decrease then a relatively constant relation. As for the US factor, prices moved at opposite direction during sometimes in the crisis, combined with a sharp decrease in dependence at the beginning of the crisis and some relatively sharp troughs; led to a decoupling. The findings for seeds show that they decoupled from Europe and the United States. This is simply due to an opposite dependence, observed in the downward movement of the beta. Moreover, seeds prices kept a relatively constant level while the equity prices were going upwards then downwards (for Europe) and upwards (for the US). As for the BRICS, the dependence was almost constant with some troughs and peaks, which created only interdependence. Semi conductors show only evidence of interdependence with Europe and the BRICS factors. The absence of contagion is due to near-zero beta with some few fluctuations. As for the US, s small decoupling and a small dependence are documented. This is probably due to a sharp decrease in dependence at the end of the crisis, which also had an opposite-side co-movement at some point. Yet the beyond the factor estimate show evidence of decoupling, suggesting that this effect could be the consequence of some other causes. As for softs, a significant factor related contagion to the US and a contagion only effect with the BRICS were detected. These are simply due to the fact that prices of softs and those equities were in the same direction. Turning to chemicals, they decoupled from Europe because 
of decreased downward dependence. As for the BRICS, the decoupling is explained by an opposite side co-movement of the prices at the beginning of the crisis. The beta with the US fluctuated near zero, which is the reason for the absence of contagion.

The results of the contagion model for the European debt crisis are reported in Table 7. Crude oil exhibits evidence of factor related contagion with Europe. This is explained by the increase in dependence at the beginning and during the second half of the crisis time, which is due to the fact that prices moved together. As for the US factor, a decoupling is documented, despite a positive dependence. While prices have the same pattern, the dependence was heading downwards, suggesting an amplified effect of the previous crises. as for the BRICS factor, no contagion is found. Natural gas decoupled from Europe because its prices and those of the European factor moved at opposite sides at the beginning of the crisis. Moreover, the dependence shows a sharp downward movement after being at a peak. For the US factor, the same result for Europe is documented. Despite the positive dependence, observed in the relatively upward shape of the beta, prices moved at opposite sides at some times during the crisis, thus creating a decoupling. For the BRICS factor, despite a negative dependence due to the fact that prices moved at opposite sides at various point of times, the results show evidence of contagion. This could be explained by the increase in dependence relatively to the pre crisis period. Electricity shows evidence of interdependence only with Europe and the BRICS. While the dependence fluctuation creates integration, the absence of sharp increases or decreases eliminates contagion. As for the US, a significantly negative gamma estimate is found, indicating decoupling despite a positive interdependence. While the latter is explained by the fact that prices move at the same direction, the reason behind decoupling is the significant decrease in dependence between electricity and US equities compared to the pre-crisis period. The findings for metals exhibit evidence of decoupling for Europe and the BRICS factor. The equity prices of both the factors and the metals prices moved at the same direction during the crisis, which is an evidence of financialization. Yet this interdependence saw sharp decreases at 
the beginning of the crisis, with some sharp troughs during it. Consequently, a decoupling was documented. For the US factor, no contagion or interdependence is recorded because of the fluctuation of the beta near zero, eliminating contagion. The prices of precious metals, US equities and BRICS stocks move at the same side. Consequently, a positive and significant dependence is found between the commodities and those stocks. As for contagion, both equities show a sharp decrease in the dependence at the beginning of the crisis, but this integration has a downward pattern with the US and up upwards one with the BRICS. As a result, precious metals decoupled from the USA and exhibited contagion with the BRICS factor. As for the European factor, a negative and weakly fluctuating dependence is documented, thus we got a significantly negative interdependence. Agricultural oils' findings show significantly negative interdependence with Europe and the USA, which is explained by an opposite side co-movement at the dawn of the crisis, and an overall downward negative dependence. Yet the high fluctuations of these integrations eliminated contagion. As for the BRICS, it seems like the similar pattern of the prices during the crisis and the various peaks of the already positive dependence created a significant contagion effect with agricultural oils. Turning our focus to feeds, their prices and those of Europe have some opposite-side co-movements at some points of the crisis time lapse. Consequently, a significantly negative interdependence is created. Yet despite being negative, the sharp increase in dependence at the beginning of the crisis and its upwards trend at the end resulted in a significant factor related contagion. As for the US factor, the opposite case is observed: the positive beta coincided with the overall similar price pattern and resulted in a significantly positive dependence. Yet the sharp decrease in this dependence at the beginning of the crisis and the overall decreasing trend at the end created a significant decoupling effect. Turning to the BRICS factor, the peak in the positive dependence and the quite similar price patterns resulted in a significant interdependence, yet no contagion or decoupling is documented. Turning to fibers, the dependence with Europe is overall positive and fluctuates around zero, which eliminates any contagion or decoupling effect, yet creating a 
significant positive interdependence. The same is observed for the BRICS, yet the sharp decrease in dependence at the dawn of the turbulent period resulted in a negative dependence. For the US factor, the prices of American stocks and fibers' prices follow the same trend. Moreover, the dependence is positive and had many peaks throughout the crises times. Consequently, a significant factor related contagion associated with a positive dependence is documented. For forestry products, the findings show significant evidence of factor related contagion despite a negative dependence with Europe. While the negative dependence is explained by the negative beta, caused by an opposite side price co-movement at the dawn of the crisis followed by a lighter similar pattern for the commodities, the graph in Figure 5-c shows a sharp increase in dependence at the first period of the crisis, thus creating contagion. For the US factor, the positive beta during the crisis reflects the relatively similar price movement pattern of the prices, yet the decoupling is caused mostly by the sharp decrease in dependence at the beginning of the trembled time lapse. The dependence between forestry products returns and those of the BRICS starts with a sharp decrease from positive to negative, then goes back to a positive and less than 1 dependence. Consequently, a significant positive integration combined with a small but significant decoupling are documented. Turning to grains, the estimation results for Europe and the United States show evidence of significantly positive dependence coupled with a decoupling. As mentioned earlier, the positive integration is explained by the fact that prices move together at the same direction, which is translated by the positive beta during the crisis. As for the decoupling, it is explained by the downwards pattern of the dependence at the beginning and at the end of the turbulent period. Speaking about the relationship with the BRICS factor, a positive dependence due to a similar direction in price movements, combined with a sharp increase in that dependence when the crisis started and some large peaks during it, creates a significant factor related contagion. The prices of live stocks and those of European and American equities co-moved in opposite direction during the first part the crisis time. Consequently, a negative interdependence is documented, observed in the neg- 
ative betas. Yet a relatively sharp increase in this dependence during the crisis combined with an upwards movement in that link created significant factor related contagion. As for the BRICS factor, the beta was mostly negative during the crisis with fluctuations around zero, which caused only negative interdependence to occur. Focusing on oil seeds, their prices move at the same direction as those of Europe and the USA as well, creating thus positive interdependence. But a downwards movement of the dependence at the beginning and the end of the crisis resulted in a significant decoupling effect. As for the BRICS factor, the dependence is overall stable with a slight downwards pattern. As a consequence, only significant negative dependence is reported. Seeds prices gave an overall constant trend while those of the US and Europe were heading downwards, which resulted in a negative interdependence. Speaking about Europe, the beta is negative and has a decreasing pattern during most of the crisis time. Thus a significant decoupling is detected. As for the US, the beta is negative and has some sharp troughs during the EDC. Consequently, a decoupling is also reported. Thus the upwards movement of the dependence made the decoupling rather small. For the BRICS factor, the overall positive upwards dependence, which also fluctuates not so far from zero, created a small but significant factor related contagion. Semi-conductors prices also show a relatively constant trend while those of all the three factors are heading downwards or upwards, which resulted in a negative dependence with Europe. Yet this dependence is almost zero in the times of the European debt crisis, thus only negative interdependence is documented for all the factors. The one for Europe is larger due to the trough in the middle of the trembled era. As for the US factor, the dependence is small and positive because of some small peaks in the dependence. Softs show evidence of significant negative interdependence with Europe and the USA. It is explained by the overall negative dependence issued from the average opposite side co-movement of the prices. The absence of significant upwards or downwards movement during the crisis, and the heavy fluctuations of the dependence eliminated the contagion effect. Finally, chemicals show evidence of factor related decoupling associated with positive dependence with all of the factors. As 
the positive integration is due to the similar trend in price co-movement of the commodity and the equities, the decoupling is explained by the sharp decrease in the dependence during the dawn of the crisis and the overall downwards trend at its end.

Now we turn our focus to the BREXIT. The results are reported in Table 8. Starting with crude oil, the findings of the contagion model for the BREXIT suggests evidence of decoupling from Europe, associated with a significant and negative dependence. This decoupling is due to the opposite side co-movement of oil and European stocks during the crisis, associated with a downward negative dependence. Moreover, oil prices during the BREXIT are much lower than during the rest of the studied period, while those of European stocks are relatively stable. As for the US factor, the relatively similar price movement pattern and the positive dependence with some large peaks throughout the crisis created significant contagion with positive dependence. The same reasoning goes for the BRICS factor, yet the dependence here is positive and having an upwards trend. Moreover, both the BRICS and oil prices had an upward trend following a drop down before the crisis. Natural gas shows practically stable positive dependence with Europe, with some light fluctuations. Consequently, a significantly positive dependence is found. While gas prices has a relatively upwards movements with lots of fluctuations, stock prices have an upwards movement as well. As for the US factor, the graphics in Figures 2 and 4 show that the positive dependence between gas and US equity prices has its peaks at the same time intervals in which the prices of both assets had their peaks. Consequently, a contagion effect is detected, associated with a significantly positive dependence. The BRICS stock prices and natural gas prices appear to have opposite side co-movement at various points during the BREXIT time. Thus a negative dependence is found. Yet the dependence is practically stable, which eliminated the contagion or decoupling effect. Electricity exhibits evidence of significant decoupling from the BREXIT because its prices moved at the opposite direction of European stocks. Furthermore, this negative dependence has a downward trend with some remarkably sharp troughs. As for the US factor, 
significant factor related contagion associated with positive dependence is documented. It is explained by the fact that prices have the same pattern during the crisis and the relatively sharp and large peaks of dependence during most of the crisis. the same result is found for the BRICS factor. Here the dependence is positive, yet it has a downward movement at the end of the crisis, which does not seem to affect the positive dependence. Moreover, for most of the crisis duration, the dependence was relatively high. Metals show significant evidence of factor related contagion with both Europe and the BRICS factors. As for the BRICS, the dependence with metals is positive and it had a sharp peak following a constant low level and a slight decrease, which explains the contagion effect. This is driven by the similar price movement pattern which magnitude is reduced by the slight price "decoupling" at the end of the crisis. The same reasoning goes for Europe, as the same elements are behind the obtained result, yet for Europe, the dependence has various sharp peaks during the crisis. For the US factor, the dependence is fluctuating near zero, which eliminated the contagion effect. For metals, a significant decoupling beyond the factors is documented. For precious metals, a significant decoupling is documented towards the European factor, associated with a negative independence. The negative dependence between the returns of these two assets explained by the opposite side co-movement at the beginning and the end of the BREXIT is behind this result. As for the US, factor related contagion is found. The dependence here shown by the fluctuations of the beta is having a decreasing trend yet it is always positive. This is the consequence of the fact that prices follow the same pattern, with a "decoupling" at the end of the crisis. Consequently, the contagion coefficient is relatively small. The contagion phenomenon is due essentially to the various sharp and large peaks of dependence, especially the beta significant increase at the dawn of the turbulent period. The same reasoning goes for the BRICS factor. Agricultural oils exhibit only evidence of interdependence with the three factors. For Europe and the United States, the negative integration is due to the fact that prices move at opposite direction. While the dependence with America and heading downwards and heavily fluctuating, it is negative 
and practically constant with Europe. As for the BRICS, their prices move at the same direction as those of agricultural oils, creating a positive dependence. Yet the fluctuation eliminated any contagion effect. Turning to feeds, they show evidence of positively significant interdependence with both the USA and the BRICS. This is due to the positive dependence between the returns of these assets, explained by their similar pattern and price co-movement for most of the crisis period. While the dependence with the US shows some relatively sharp peaks that follow a dropdown; which created contagion effect; the dependence with the BRICS factor was relatively stable. Consequently, no significant contagion or decoupling is detected. As for the European factor, there was an important opposite side co-movement of prices between its equities and feeds prices which created a negative but practically stable dependence. Consequently, only significant and negative interdependence is detected with Europe. Turning our focus to fibers, their prices have an overall similar pattern as the average of the European factor equities, but no dependence is documented, as the beta is almost zero during the entire crisis. As a result, only significant interdependence is documented. As for the US factor, its prices and those of fibers move at the same direction, with a low positive dependence exhibiting few small peaks during the crisis, thus a small factor related contagion effect is documented. The same observation concerning price movements is made for the BRICS factor. However, the dependence between equity returns of the BRICS and those of fibers commodities is zero during the entire crisis period, with a very sharp trough at the end. This resulted in a significant contagion effect without interdependence associated with it. Forestry products show evidence of significant decoupling from Europe associated with a negative dependence. By looking at the trend of both the assets' prices, it is obvious that they are not moving at the same direction. This negative dependence had a sharp and significant decrease during the crisis, which explains the decoupling. As for the US factor and the BRICS factor, they exhibit a significantly positive integration followed by a significant factor related contagion. While American stock prices and forestry products prices have a similar pattern in their co-movement 
- which created the positive dependence, which sharp peaks lead to significant contagion; there are some time intervals during which BRICS equity prices and commodity prices move at opposite directions, thus the contagion coefficients are relatively small, despite being significant (this is what made the dependence positive yet fluctuating not so far from zero, with some peaks at some points of time). Grains prices move at the same direction as those of all the three factors, which resulted in a positive dependence between the commodity and the equities. This dependence shows some upwards significant movements at some parts of time during the crisis. Besides, it is relatively higher than its level before the crisis. As a result, a significant factor related contagion effect is documented from Europe, the United States and the BRICS to grains during the BREXIT. Turning to live stocks, their prices move at the opposite direction of those of all the three factors. Consequently, a negative and significant interdependence is documented. Furthermore, the dependence of live stocks with all the equity factors is relatively constant around zero during the crisis, with a sharp trough at the end (for the US factor) and in the middle of the BREXIT time interval (for Europe and the BRICS). This resulted in a significant decoupling of live stocks from all the factors during the crisis. When we focus on oil seeds, we observe that their prices start by moving at opposite direction with those of the three factors, but this happens only for a short period of time at the dawn of the crisis. Afterwards, prices start to follow a similar pattern. As a result, a significant and positive dependence is documented. Turning to the dependence analysis, it is seen that oil seeds dependence with Europe has an increase at the beginning of the crisis and then it has a cluster of peaks. As for the US factor, the dependence starts with a sharp increase following a small drop down, with some peaks during the crisis. The same is said about the BRICS factor. These observations explain the significant contagion effect that was detected towards all the factors. Yet the practically overall stable dependence with the BRICS made the contagion coefficient estimate rather small. The results for seeds show only significant negative interdependence towards Europe, despite the similar trend in price co-movement. This negative interdependence could 
be explained by the decreasing pattern of the dependence between the returns of both of the assets during the crisis. This also could be the reason behind the absence of a contagion or decoupling effect. As for the BRICS factor, the similar price co-movement trend created a significant and positive integration, yet the fluctuations of the dependence, observed in peaks and troughs having almost the same magnitude, eliminated the contagion effect. For the US factor, a significant factor related contagion effect is documented, despite a negative dependence. Contagion is simply explained by the increasing pattern of the dependence, especially the sharp increases at the beginning of the crisis time lapse. Semi-conductors exhibit evidence of significant interdependence only, with no contagion or decoupling documented. The absence of these two phenomena is due to the fluctuation of the dependence around zero. While semi-conductors' prices and those of Europe and the BRICS move at opposite sides; creating a negative dependence; the opposite case is observed for price movement with Europe. Consequently, a positive dependence with the European factor is documented. Focusing now of softs, figure 2 shows that their prices and those of the three equity factors move at opposite directions, which created a negative interdependence. However, this negative interdependence is significant for Europe and the United states only, as neither the integration nor the contagion estimate is significant for the BRICS factor. This is explained by the heavy fluctuations of the beta between relatively low negative and positive values. As for the USA, the sharp decrease in dependence at the beginning of the crisis resulted in the significance of the interdependence, yet its stable pattern during the rest of the BREXIT time lapse eliminated the decoupling or contagion effect. The dependence with Europe has a significant decrease during the crisis, which created a decoupling effect. The findings for chemicals show significantly positive interdependence effect between them and all the factors, which is explained by the similar trend in price co-movement. Yet the dependence with Europe and America fluctuate around zero, which resulted in the absence of contagion or decoupling effect. However, the presence of several significant increases in the dependence between chemicals and the BRICS resulted in a significant factor 
related contagion between the returns of these two assets.

\section{Conclusion}

Since the Asian crisis of 1997, various studies have documented evidence of equity market contagion (Kenourgios et al. (2011), Bekaert Harvey,(2003). Bekaert et al. (2014)). When a crisis hits in one market, these shocks are transmitted from one market to another by a variety of transmission channels (Rigobon (2002), Claessens and Forbes (2004)). This phenomenon would push investors to seek protection from their portfolios from the negative effects of the crises. Consequently, market participants would seek diversification by investing in other asset classes, notably commodities. Lately, Irwin and Sanders (2011) mention a phenomenon called financializaion of commodities. This is noticed mainly during the great recession, when institutional investors turned their investment focus on commodities for speculative and hedging reasons, pushing their prices up. Basak and Pavlova $(2013,2016)$ proved this issue theoretically by presenting a model confirming that the increase in demand made by institutions for commodities pushed their prices up, alongside their volatilities, correlations and their correlations with the equity markets. Furthermore, various empirical studies document this equity-commodity shock transmission during crisis periods.

Based on these facts, we attempted to check for the existence of contagion between various equities representing three regions: the USA, Western Europe and the BRICS as well as sixteen categories of commodities (Crude Oil, Natural Gas, Electricity, Metals, Precious Metals, Agricultural Oils, Chemicals, Feeds, Fibers, Forestry Products, Grains, Live Stocks, Oil Seeds, Seeds, Semi-Conductors, and Softs). These effects are examined for four crises (the global financial crisis, the Irish banking crisis, the European debt crisis and the BREXIT). To do so, we used the DCC GARCH and the international three-factor CAPM of Bekaert

et al. (2014). Our findings suggest that almost all of the commodities show 
evidence of decoupling from the global financial crisis, the Irish banking crisis and European debt crisis towards all the factors. The Irish banking crisis and the European debt crisis, which are considered as a consequence of the global financial crisis, continued with the initial decoupling effect. When it comes for the BREXIT, investors were already aware of the equity-commodity relationship. Consequently, they started investing in them to protect their portfolios, thus creating a positive contagion effect.

The main contribution of our study is that, to the best of our knowledge, this is the first study to examine the phenomenon of contagion between the mentioned equity markets and that variety of commodities for different crises at one time. Consequently, it opens the gates for further research about the commodities in which investors should put their money into. Intuitively, the increase in correlations between these various assets increases their risk, thus it is important to choose the appropriate components of one's portfolio in order to optimize it and minimize the negative effects of the crises to the possible maximum.

\section{References}

[1] N. Barberis, A. Shleifer, Style investing, Journal of financial Economics 68 (2) (2003) 161-199.

[2] S. Basak, A. Pavlova, Asset prices and institutional investors, American Economic Review 103 (5) (2013) 1728-58.

[3] S. Basak, A. Pavlova, A model of financialization of commodities, The Journal of Finance 71 (4) (2016) 1511-1556.

[4] G. Bekaert, C. R. Harvey, Time-varying world market integration, the Journal of Finance 50 (2) (1995) 403-444.

[5] G. Bekaert, C. R. Harvey, Market integration and contagion, Tech. rep., National Bureau of Economic Research (2003).

[6] G. Bekaert, M. Ehrmann, M. Fratzscher, A. Mehl, The global crisis and equity market contagion, The Journal of Finance 69 (6) (2014) 2597-2649. 
[7] S. Bekiros, D. K. Nguyen, L. S. Junior, G. S. Uddin, Information diffusion, cluster formation and entropy-based network dynamics in equity and commodity markets, European Journal of Operational Research 256 (3) (2017) 945-961.

[8] T. Berger, G. S. Uddin, On the dynamic dependence between equity markets, commodity futures and economic uncertainty indexes, Energy Economics 56 (2016) 374-383.

[9] G. Blau, Some aspects of the theory of futures trading, The Review of Economic Studies 12 (1) (1944) 1-30.

[10] B. Büyükşahin, M. A. Robe, Speculators, commodities and cross-market linkages, Journal of International Money and Finance 42 (2014) 38-70.

[11] K. J. Forbes, S. Claessens, International financial contagion: The theory, evidence and policy implications, in: conference" The IMF's role in emerging markets economies" in Amesterdam, 2004, p. 01.

[12] K. Guesmi, K. Nguyen, International capm and regional integration factors: Evidence from some european emerging countries, Applied Economics 46 (11) (2014) 1279-1290.

[13] M. Z. Hasan, Transmission of international energy price shocks to australian stock market and its implications for portfolio formation, Asian Economic and Financial Review 7 (4) (2017) 393.

[14] S. H. Irwin, D. R. Sanders, Index funds, financialization, and commodity futures markets, Applied Economic Perspectives and Policy 33 (1) (2011) $1-31$.

[15] I. Jebabli, M. Arouri, F. Teulon, On the effects of world stock market and oil price shocks on food prices: An empirical investigation based on tvp-var models with stochastic volatility, Energy Economics 45 (2014) 66-98. 
[16] X. Jin, X. An, Global financial crisis and emerging stock market contagion: A volatility impulse response function approach, Research in International Business and Finance 36 (2016) 179-195.

[17] D. Kenourgios, A. Samitas, N. Paltalidis, Financial crises and stock market contagion in a multivariate time-varying asymmetric framework, Journal of International Financial Markets, Institutions and Money 21 (1) (2011) $92-106$.

[18] R. Khalfaoui, M. Boutahar, H. Boubaker, Analyzing volatility spillovers and hedging between oil and stock markets: Evidence from wavelet analysis, Energy Economics 49 (2015) 540-549.

[19] R. López, Volatility contagion across commodity, equity, foreign exchange and treasury bond markets, Applied Economics Letters 21 (9) (2014) 646650.

[20] W. Mensi, M. Beljid, A. Boubaker, S. Managi, Correlations and volatility spillovers across commodity and stock markets: Linking energies, food, and gold, Economic Modelling 32 (2013) 15-22.

[21] D. K. Nguyen, A. Sensoy, R. M. Sousa, G. S. Uddin, Us equity and commodity futures markets: Hedging or financialization?, Energy Economics (2020) 104660.

[22] F. Nobel, Integration of the equity market in the european economic and monetary union (2016).

[23] R. Rigobon, International financial contagion: Theory and evidence in evolution, cfa (2002).

[24] R. P. Roy, S. S. Roy, Financial contagion and volatility spillover: An exploration into indian commodity derivative market, Economic Modelling 67 (2017) 368-380. 
[25] X. Wen, Y. Wei, D. Huang, Measuring contagion between energy market and stock market during financial crisis: A copula approach, Energy economics 34 (5) (2012) 1435-1446.

$[1,2,3,4,5,6,7,8,9,10,11,12,13,14,15,16,17,18,19,20,21,22,23,24,25]$

\section{Appendices}

$\mathrm{r} 15 \mathrm{~cm}$

Table 1: Descriptive statistics

\begin{tabular}{|c|c|c|c|c|c|c|c|c|c|}
\hline Variable & Obs & Min & Mean & Max & Std Dev & Skewness & Kurtosis & JQ-Bera & ARCH Test \\
\hline Crude oil & 617 & -26.336 & -0.037 & 24.457 & 4.976 & 0.124 & 0.546 & 0.287 & $58.477^{* * *}$ \\
\hline Natural Gas & 617 & -109.47 & -0.152 & 100.05 & 12.729 & 0.409 & 1.074 & 1.432 & 0.181 \\
\hline Electricity & 617 & -14.198 & -0.014 & 19.45 & 4.188 & -0.524 & 0.771 & 1.305 & $9.135^{* * *}$ \\
\hline Metals & 617 & -14.755 & -0.009 & 14.588 & 1.848 & 0.114 & 1.376 & 1.569 & 1.391 \\
\hline Precious Metals & 617 & -10.704 & 0.045 & 8.073 & 2.352 & 0.074 & 1.039 & 0.888 & $45.703^{* * *}$ \\
\hline Agricultural Oils & 617 & -9.922 & 0.015 & 6.955 & 1.99 & 0.227 & 0.731 & 0.587 & $21.859^{* * *}$ \\
\hline Feeds & 617 & -11.602 & 0.055 & 8.519 & 2.418 & -0.572 & 0.694 & 1.372 & $12.607^{* * *}$ \\
\hline Fibers & 617 & -24.308 & 0.114 & 41.006 & 2.777 & $1.304^{* *}$ & 1.685 & $7.392^{* *}$ & 0.003 \\
\hline Forestry Products & 617 & -8.589 & 0.0383 & 4.309 & 1.141 & 0.435 & 0.495 & 0.766 & 0.0243 \\
\hline Grains & 617 & -12.714 & 0.034 & 8.602 & 2.469 & -0.150 & $1.869^{* * *}$ & $92.171^{* * *}$ & $8.949^{* * *}$ \\
\hline Live Stocks & 617 & -32.314 & -0.049 & 18.962 & 2.757 & 0.259 & 0.444 & 0.360 & 2.752 \\
\hline Oil Seeds & 617 & -14.039 & 0.027 & 12.263 & 2.879 & -0.502 & 0.0387 & 0.758 & $14.526^{* * *}$ \\
\hline Seeds & 617 & -29.691 & 0.063 & 18.394 & 3.453 & $0.923^{*}$ & 0.013 & 2.554 & $6.387^{* * *}$ \\
\hline Semi Conductors & 617 & -33.178 & -0.168 & 19.924 & 2.969 & 0.595 & 0.297 & 1.132 & 0.977 \\
\hline Softs & 617 & -13.204 & 0.049 & 18.296 & 3.043 & -0.551 & 0.265 & 0.967 & $9.409^{* * *}$ \\
\hline Chemicals & 617 & -12.439 & -0.039 & 12.985 & 2.642 & $-0.525^{* * *}$ & $3.612^{* * *}$ & $363.66^{* * *}$ & $9.008^{* * *}$ \\
\hline
\end{tabular}


Table 2: Stationnarity Test

\begin{tabular}{|c|c|c|c|}
\hline Critical Values & -2.56572 & -1.94093 & -1.61663 \\
\hline Critical Levels & $1 \%$ & $5 \%$ & $10 \%$ \\
\hline Crude Oil & \multicolumn{3}{|c|}{-2.23777} \\
\hline Natural Gas & \multicolumn{3}{|c|}{-3.34925} \\
\hline Electricity & \multicolumn{3}{|c|}{-1.01726} \\
\hline Metals & -2.176 \\
\hline Precious Metals & -1.68662 \\
\hline Agricultural Oils & -1.75441 \\
\hline Feeds & 0.424427 \\
\hline Fibers & -1.58284 \\
\hline Forestry Products & -13.588 \\
\hline Grains & -1.17113 \\
\hline Live Stocks & -1.2866 \\
\hline Oil Seeds & -0.777493 \\
\hline Seeds & -1.16272 \\
\hline Semi Conductors & -2.22197 \\
\hline Softs & -10.1683 \\
\hline Chemicals & \\
\hline
\end{tabular}




\begin{tabular}{c|ccc}
\multicolumn{4}{c}{ Table 3: Correlation Matrix } \\
\hline *** & EUR Factor & US Factor & BRICS Factor \\
\hline EUR Factor & 1.000 & & \\
US Factor & 0.0717 & 1.0000 & \\
BRICS FACTOR & -0.0511 & $0.2825^{*}$ & 1.0000 \\
Crude Oil & $-0.1405^{*}$ & $0.0845^{*}$ & $0.1262^{*}$ \\
Natural Gas & $0.8468^{*}$ & -0.0018 & $-0.0847^{*}$ \\
Electricity & -0.0166 & $0.0843^{*}$ & $0.1056^{*}$ \\
Metals & 0.0208 & 0.0458 & 0.0264 \\
Precious Metals & -0.0002 & $0.0801^{*}$ & $0.1038^{*}$ \\
Agricultural Oils & 0.0076 & 0.0177 & $0.0918^{*}$ \\
Chemicals & 0.0129 & 0.0422 & 0.0635 \\
Feeds & -0.0068 & $0.1187^{*}$ & 0.0605 \\
Fibers & -0.0307 & 0.0406 & 0.0045 \\
Foresty Products & -0.0176 & $0.1171^{*}$ & 0.0173 \\
Grains & 0.0270 & $0.1233^{*}$ & $0.1085^{*}$ \\
Livestock & -0.0072 & -0.0021 & -0.0010 \\
Oil Seeds & 0.0105 & $0.1280^{*}$ & $0.0969^{*}$ \\
Seeds & -0.0007 & -0.0189 & 0.0364 \\
Semi Conductors & 0.0038 & 0.0024 & 0.0199 \\
Softs & -0.0012 & 0.0322 & 0.0234 \\
\hline
\end{tabular}


Table 4: Interdependence Model

\begin{tabular}{|c|c|c|c|}
\hline Variable & EUR Factor & US Factor & BRICS Factor \\
\hline Crude Oil & $-20.841^{* * *}$ & 0.665 & $0.642^{* *}$ \\
\hline Natural Gas & $628.293^{* * *}$ & $-2.762^{* *}$ & -0.817 \\
\hline Electricity & -2.075 & 0.539 & $0.459^{* *}$ \\
\hline Metals & 0.919 & 0.161 & 0.0529 \\
\hline Precious Metals & 0.063 & 0.264 & $0.261^{* *}$ \\
\hline Agricultural Oils & 0.757 & -0.062 & 0.239 \\
\hline Feeds & -0.961 & $0.539^{* * *}$ & 0.079 \\
\hline Fibers & -2.798 & 0.253 & -0.038 \\
\hline Forestry Products & -0.900 & $0.244^{* * *}$ & -0.026 \\
\hline Grains & 1.731 & 0.487 & $0.254^{*}$ \\
\hline Livestock & -0.465 & -0.013 & -0.002 \\
\hline Oil Seeds & 0.516 & 0.623 & 0.244 \\
\hline Seeds & 0.369 & -0.199 & 0.182 \\
\hline Semi Conductors & 0.355 & -0.029 & 0.039 \\
\hline Softs & -0.236 & 0.177 & 0.049 \\
\hline Chemicals & 0.836 & 0.142 & 0.134 \\
\hline
\end{tabular}


$\mathrm{r} 15 \mathrm{~cm}$

Table 5: Contagion Model: Global Financial Crisis

\begin{tabular}{|c|c|c|c|c|c|c|c|}
\hline \multicolumn{8}{|c|}{ Global Financial Crisis } \\
\hline$* * *$ & \multicolumn{2}{|c|}{ EUR Factor } & \multicolumn{2}{|c|}{ US Factor } & \multicolumn{2}{|c|}{ BRICS Factor } & \multirow{2}{*}{$\begin{array}{c}\text { Other } \\
\mu\end{array}$} \\
\hline$* * *$ & $\alpha$ & $\beta$ & $\alpha$ & $\beta$ & $\alpha$ & $\beta$ & \\
\hline Crude Oil & 0.474 & $-22.941^{* * *}$ & $-0.081^{* * *}$ & $0.496^{* * *}$ & 0.018 & $0.832^{* * *}$ & 0.304 \\
\hline Natural Gas & $-121.218^{* *}$ & $440.046^{* * *}$ & $-0.215^{* *}$ & $0.495^{* * *}$ & $0.868^{* * *}$ & $-2.752^{* * *}$ & 0.105 \\
\hline Electricity & $-0.441^{*}$ & $-3.761^{* * *}$ & $-0.039^{* *}$ & $0.379^{* * *}$ & 0.020 & $0.503^{* * *}$ & 0.278 \\
\hline Metals & $-0.317^{* * *}$ & $0.852^{* * *}$ & $-7.451 e^{-6}$ & $-0.009^{* * *}$ & $-0.034^{* * *}$ & $0.099^{* * *}$ & 0.017 \\
\hline Precious Metals & $-0.203^{*}$ & $-1.747^{* * *}$ & $-0.021^{* * *}$ & $0.186^{* * *}$ & 0.007 & $0.225^{* * *}$ & $0.362^{*}$ \\
\hline Agricultural Oils & $-0.264^{* * *}$ & $-1.158^{* * *}$ & $-2.05 e^{-6}$ & $-0.268^{* * *}$ & $0.036^{* * *}$ & $0.126^{* * *}$ & 0.271 \\
\hline Feeds & 0.072 & $-2.787^{* * *}$ & $-0.054^{* * *}$ & $0.337^{* * *}$ & 0.001 & $0.077^{* * *}$ & 0.218 \\
\hline Fibers & -0.436 & $0.628^{* * *}$ & $-0.069^{* *}$ & $0.392^{* * *}$ & 0.070 & $-0.059^{*}$ & 0.324 \\
\hline Forestry Products & 0.142 & $-1.80^{* * *}$ & $-0.036^{* * *}$ & $0.222^{* * *}$ & $-5.613 e^{-5}$ & $0.035^{* * *}$ & -0.013 \\
\hline Grains & $-0.229^{*}$ & $2.781^{* * *}$ & $-0.043^{* * *}$ & $0.404^{* * *}$ & 0.004 & $0.250^{* * *}$ & 0.190 \\
\hline Livestock & $2.101^{* * *}$ & $-8.056^{* * *}$ & $0.113^{* * *}$ & $-0.280^{* * *}$ & $0.049^{* *}$ & $-0.081^{* * *}$ & 0.157 \\
\hline Oil Seeds & $-0.142^{*}$ & $0.792^{* * *}$ & $-0.078^{* * *}$ & $0.536^{* * *}$ & -0.007 & $0.224^{* * *}$ & 0.298 \\
\hline Seeds & $-1.25^{* * *}$ & $-3.313^{* * *}$ & $-0.083^{* * *}$ & $-0.141^{* * *}$ & -0.004 & $0.081^{* * *}$ & 0.349 \\
\hline Semi Conductors & $-2.897^{* * *}$ & $-7.731^{* * *}$ & -0.038 & $0.079^{* * *}$ & 0.026 & $-0.049^{* * *}$ & $-0.596^{* *}$ \\
\hline Softs & $0.256^{*}$ & $-1.601^{* * *}$ & $0.025^{* * *}$ & $-0.065^{* * *}$ & 0.006 & 0.001 & 0.285 \\
\hline Chemicals & $-0.370^{* * *}$ & $0.441^{* * *}$ & $-0.023^{* *}$ & $0.066^{* * *}$ & $-0.070^{* * *}$ & $0.322^{* * *}$ & 0.262 \\
\hline
\end{tabular}


$\mathrm{r} 15 \mathrm{~cm}$

Table 6: Contagion Model: Irish Banking Crisis

\begin{tabular}{|c|cc|cc|cc|c|}
\hline \multicolumn{7}{|c|}{ Global Financial Crisis } \\
\hline$* * *$ & EUR Factor & \multicolumn{2}{c|}{ US Factor } & \multicolumn{2}{c|}{ BRICS Factor } & Other \\
\hline$* * *$ & $\alpha$ & $\beta$ & $\alpha$ & $\beta$ & $\alpha$ & $\beta$ & $\mu$ \\
\hline Crude Oil & $-3.610^{* * *}$ & $-22.026^{* * *}$ & -0.014 & $0.473^{* * *}$ & $0.187^{* * *}$ & $0.798^{* * *}$ & -0.037 \\
\hline Natural Gas & -29.424 & $407.571^{* * *}$ & -0.172 & $0.463^{* * *}$ & 0.425 & $-2.564^{* * *}$ & -0.149 \\
\hline Electricity & $-1.120^{* * *}$ & $-3.665^{* * *}$ & 0.005 & $0.365^{* * *}$ & $0.111^{* * *}$ & $0.486^{* * *}$ & -0.084 \\
\hline Metals & $-0.184^{* *}$ & $0.789^{* * *}$ & 0.004 & $-0.010^{* * *}$ & -0.015 & $0.092^{* * *}$ & -0.092 \\
\hline Precious Metals & $-0.342^{* * *}$ & $-1.739^{* * *}$ & $-0.023^{* * *}$ & $0.185^{* * *}$ & 0.013 & $0.225^{* * *}$ & $0.436^{*}$ \\
\hline Agricultural Oils & $-0.433^{* * *}$ & $-1.151^{* * *}$ & 0.005 & $-0.269^{* * *}$ & $0.060^{* * *}$ & $0.124^{* * *}$ & 0.186 \\
\hline Feeds & -0.217 & $-2.717^{* * *}$ & $-0.036^{* * *}$ & $0.328^{* * *}$ & $0.017^{* * *}$ & $0.073^{* * *}$ & 0.113 \\
\hline Fibers & -0.583 & $0.612^{* * *}$ & -0.026 & $0.376^{* * *}$ & 0.059 & $-0.049^{*}$ & $0.609^{* *}$ \\
\hline Forestry Products & $-0.252^{* *}$ & $-1.702^{* * *}$ & -0.008 & $0.212^{* * *}$ & 0.001 & $0.035^{* * *}$ & 0.042 \\
\hline Grains & 0.018 & $2.704^{* * *}$ & $-0.032^{* *}$ & $0.397^{* * *}$ & $0.028^{* * *}$ & $0.245^{* * *}$ & 0.066 \\
\hline Livestock & $1.382^{* *}$ & $-7.678^{* * *}$ & $0.101^{* * *}$ & $-0.265^{* * *}$ & 0.039 & $-0.074^{* * *}$ & 0.176 \\
\hline Oil Seeds & -0.019 & $0.751^{* * *}$ & $-0.086^{* * *}$ & $0.530^{* * *}$ & 0.009 & $0.220^{* * *}$ & 0.023 \\
\hline Seeds & $-1.824^{* * *}$ & $-3.327^{* * *}$ & $-0.094^{* * *}$ & $-0.147^{* * *}$ & 0.002 & $0.079^{* * *}$ & -0.109 \\
\hline Semi Conductors & -1.449 & $-8.349^{* * *}$ & $-0.063^{* *}$ & $0.080^{* * *}$ & 0.008 & $-0.043^{* * *}$ & $0.532^{*}$ \\
\hline Softs & 0.155 & $-1.552^{* * *}$ & $0.026^{* * *}$ & $-0.062^{* * *}$ & $0.021^{* *}$ & -0.001 & 0.025 \\
\hline Chemicals & $-0.290^{* * *}$ & $0.384^{* * *}$ & -0.007 & $0.060^{* * *}$ & $-0.035^{* * *}$ & $0.307^{* * *}$ & 0.027 \\
\hline
\end{tabular}


$\mathrm{r} 15 \mathrm{~cm}$

Table 7: Contagion Model: European Debt Crisis

\begin{tabular}{|c|c|c|c|c|c|c|c|}
\hline \multicolumn{8}{|c|}{ Global Financial Crisis } \\
\hline$* * *$ & \multicolumn{2}{|c|}{ EUR Factor } & \multicolumn{2}{|c|}{ US Factor } & \multicolumn{2}{|c|}{ BRICS Factor } & \multirow{2}{*}{$\begin{array}{c}\text { Other } \\
\mu\end{array}$} \\
\hline$* * *$ & $\alpha$ & $\beta$ & $\alpha$ & $\beta$ & $\alpha$ & $\beta$ & \\
\hline Crude Oil & $3.767^{* *}$ & $-23.367^{* * *}$ & $-0.118^{* * *}$ & $0.488^{* * *}$ & 0.004 & $0.837^{* * *}$ & 0.403 \\
\hline Natural Gas & $-230.247^{* * *}$ & $436.570^{* * *}$ & $-0.228^{*}$ & $0.461^{* * *}$ & $1.050^{* * *}$ & $-2.635^{* * *}$ & -0.365 \\
\hline Electricity & 0.404 & $-3.964^{* * *}$ & $-0.112^{* * *}$ & $0.384^{* * *}$ & -0.028 & $0.514^{* * *}$ & 0.431 \\
\hline Metals & $-0.386^{* * *}$ & $0.809^{* * *}$ & -0.008 & $-0.008^{* * *}$ & $-0.042^{* * *}$ & $0.095^{* * *}$ & 0.021 \\
\hline Precious Metals & -0.082 & $-1.799^{* * *}$ & $-0.038^{* * *}$ & $0.185^{* * *}$ & $0.028^{* * *}$ & $0.223^{* * *}$ & 0.184 \\
\hline Agricultural Oils & 0.028 & $-1.247^{* * *}$ & 0.009 & $-0.269^{* * *}$ & $0.015^{* *}$ & $0.135^{* * *}$ & 0.158 \\
\hline Feeds & $0.641^{* * *}$ & $-2.862^{* * *}$ & $-0.073^{* * *}$ & $0.331^{* * *}$ & -0.004 & $0.078^{* * *}$ & 0.075 \\
\hline Fibers & -0.077 & $0.500^{* * *}$ & $0.083^{* *}$ & $0.357^{* * *}$ & 0.067 & $-0.047^{* * *}$ & 0.031 \\
\hline Forestry Products & $0.231^{*}$ & $-1.791^{* * *}$ & $-0.025^{* * *}$ & $0.214^{* * *}$ & $0.008^{* *}$ & $0.034^{* * *}$ & -0.207 \\
\hline Grains & $-0.357^{* *}$ & $2.763^{* * *}$ & $-0.054^{* * *}$ & $0.398^{* * *}$ & $0.020^{*}$ & $0.248^{* * *}$ & 0.340 \\
\hline Livestock & $1.599^{* *}$ & $-7.630^{* * *}$ & $0.070^{* *}$ & $-0.255^{* * *}$ & 0.013 & $-0.067^{* * *}$ & 0.161 \\
\hline Oil Seeds & $-0.210^{* *}$ & $0.779^{* * *}$ & $-0.117^{* * *}$ & $0.529^{* * *}$ & -0.013 & $0.224^{* * *}$ & 0.178 \\
\hline Seeds & $-0.785^{* *}$ & $-3.593^{* * *}$ & $-0.067^{* * *}$ & $-0.157^{* * *}$ & $0.030^{* * *}$ & $0.075^{* * *}$ & 0.486 \\
\hline Semi Conductors & 0.002 & $-8.656^{* * *}$ & -0.034 & $0.071^{* * *}$ & -0.005 & $-0.040^{* * *}$ & -0.218 \\
\hline Softs & 0.181 & $-1.546^{* * *}$ & -0.002 & $-0.056^{* * *}$ & -0.008 & 0.004 & -0.142 \\
\hline Chemicals & $-0.229^{* *}$ & $0.358^{* * *}$ & $-0.027^{* *}$ & $0.063^{* * *}$ & $-0.051^{* * *}$ & $0.308^{* * *}$ & 0.336 \\
\hline
\end{tabular}


$\mathrm{r} 15 \mathrm{~cm}$

Table 8: Contagion Model: BREXIT

\begin{tabular}{|c|cc|cc|cc|c|}
\hline \multicolumn{7}{|c|}{ Global Financial Crisis } \\
\hline$* * *$ & EUR Factor & \multicolumn{2}{c|}{ US Factor } & BRICS Factor & Other \\
\hline$* * *$ & $\alpha$ & $\beta$ & $\alpha$ & $\beta$ & $\alpha$ & $\beta$ & $\mu$ \\
\hline Crude Oil & $-7.213^{* * *}$ & $-21.296^{* * *}$ & $0.133^{* * *}$ & $0.443^{* * *}$ & $0.273^{* * *}$ & $0.782^{* * *}$ & 0.123 \\
\hline Natural Gas & 45.529 & $391.913^{* * *}$ & $0.298^{* * *}$ & $0.364^{* * *}$ & -0.392 & $-2.393^{* * *}$ & 0.540 \\
\hline Electricity & $-1.336^{* * *}$ & $-3.626^{* * *}$ & $0.114^{* * *}$ & $0.343^{* * *}$ & $0.225^{* * *}$ & $0.463^{* * *}$ & 0.203 \\
\hline Metals & $0.555^{* * *}$ & $0.635^{* * *}$ & -0.006 & $-0.007^{* * *}$ & $0.105^{* * *}$ & $0.066^{* * *}$ & $0.356^{* *}$ \\
\hline Precious Metals & $-0.200^{*}$ & $-1.770^{* * *}$ & $0.025^{* * *}$ & $0.174^{* * *}$ & $0.0266^{* * *}$ & $0.222^{* * *}$ & 0.210 \\
\hline Agricultural Oils & 0.025 & $-1.248^{* * *}$ & 0.011 & $-0.270^{* * *}$ & 0.005 & $0.136^{* * *}$ & -0.171 \\
\hline Feeds & -0.179 & $-2.726^{* * *}$ & $0.056^{* * *}$ & $0.308^{* * *}$ & 0.006 & $0.076^{* * *}$ & -0.310 \\
\hline Fibers & -0.138 & $0.517^{* * *}$ & $0.067^{* *}$ & $0.356^{* * *}$ & $-0.141^{* *}$ & -0.007 & 0.452 \\
\hline Forestry Products & $-0.532^{* * *}$ & $-1.646^{* * *}$ & $0.068^{* * *}$ & $0.196^{* * *}$ & $0.016^{* * *}$ & $0.032^{* * *}$ & 0.071 \\
\hline Grains & $0.566^{* * *}$ & $2.591^{* * *}$ & $0.089^{* * *}$ & $0.372^{* * *}$ & $0.062^{* * *}$ & $0.238^{* * *}$ & -0.104 \\
\hline Livestock & $-2.890^{* * *}$ & $-6.787^{* * *}$ & $-0.135^{* * *}$ & $-0.216^{* * *}$ & $-0.088^{* * *}$ & $-0.047^{* * *}$ & -0.322 \\
\hline Oil Seeds & $0.158^{* *}$ & $0.714^{* * *}$ & $0.051^{* *}$ & $0.501^{* * *}$ & $0.019^{*}$ & $0.218^{* * *}$ & -0.292 \\
\hline Seeds & 0.105 & $-3.735^{* * *}$ & $0.050^{* * *}$ & $-0.178^{* * *}$ & 0.011 & $0.077^{* * *}$ & 0.029 \\
\hline Semi Conductors & 0.458 & $-8.751^{* * *}$ & -0.014 & $0.069^{* * *}$ & 0.016 & $-0.044^{* * *}$ & 0.432 \\
\hline Softs & $-0.448^{* * *}$ & $-1.426^{* * *}$ & 0.008 & $-0.058^{* * *}$ & 0.011 & 0.001 & -0.135 \\
\hline Chemicals & 0.067 & $0.309^{* * *}$ & -0.006 & $0.060^{* * *}$ & $0.077^{* * *}$ & $0.284^{* * *}$ & 0.125 \\
\hline
\end{tabular}

